\title{
CUIDADO CRÍTICO E CRIATIVO: CONTRIBUIÇÕES DA EDUCAÇÃO CONSCIENTIZADORA DE PAULO FREIRE PARA A ENFERMAGEM ${ }^{\star}$
}

\author{
CRITICAL AND CREATIVE CARE: CONTRIBUTION OF PAULO FREIRE \\ EDUCATION FOR NURSING
}

\author{
CUIDADO CRÍTICO Y CREATIVO: CONTRIBUCIONES DE LA \\ EDUCACIÓN DE PAULO FREIRE PARA LA ENFERMERÍA
}

\author{
Natália Rocha Chagas** \\ IsLane Costa Ramos ${ }^{* * *}$ \\ LÚCIA DE FÁtIMA DA SILVA ${ }^{* * * *}$ \\ Ana Ruth Macêdo Monteiro ${ }^{* * * * *}$ \\ Ana Virgínia de Melo Fialho******
}

\begin{abstract}
RESUMO
O presente artigo discute a possibilidade de transformação da prática de enfermagem por meio do cuidado crítico e criativo, propondo a educação em saúde como ferramenta para este fim. Apresenta ainda, em linhas gerais, a proposta educativa de Paulo Freire, ressaltando como os seus princípios podem superar o modelo de educação em saúde vigente, que pouco colabora para a emancipação dos sujeitos envolvidos no processo de cuidado.
\end{abstract}

Palavras chave: Cuidado de enfermagem; educação em saúde; educação em enfermagem.

\begin{abstract}
This article discuss the possibility of transformation of nursing practice through critical and creative care, and propose the health education as instrument for this. It shows the Paulo Freire education proposal, pointing out how his principles can overcome the current health education model, that scarcely collaborate with the individual independence involved in care process.
\end{abstract}

Key words: Nursing care; health education; nursing education.

\footnotetext{
* Trabalho desenvolvido na disciplina O Cuidado em Si, do Curso de Mestrado Acadêmico Cuidados Clínicos em Saúde (CMACCLIS) da Universidade Estadual do Ceará (UECE).

** Enfermeira. Aluna do CMACCLIS da UECE. Fortaleza, Brasil. Especialista em Neonatologia. Pesquisadora do Grupo de Pesquisa Educação, Saúde, Sociedade (GRUPESS). Bolsista CAPES. Autora para correspondência: Rua Dom Joaquim, 442 Centro CEP: 60110-100 E-mail: nataliarocha.ce@superig.com.br

*** Enfermeira. Aluna do CMACCLIS da UECE. Fortaleza, Brasil. Especialista em Nefrologia. Pesquisadora do Grupo de Pesquisa Saúde Mental, Família e Práticas Alternativas de Saúde. Bolsista Funcap.E-mail: islane_ramos@uol.com.br

$* * * *$ Enfermeira. Mestra e doutora em Enfermagem. Professora do curso de graduação em Enfermagem e do CMACCLIS da UECE. Enfermeira do Hospital de Messejana, Fortaleza, Brasil. Pesquisadora do GRUPESS. E-mail: luciadefatima.ce@ terra.com.br

${ }_{* * * * *}$ Enfermeira. Mestra e doutora em Enfermagem. Professora do curso de graduação em Enfermagem e do CMACCLIS da UECE. Enfermeira do Hospital de Messejana, Fortaleza, Brasil. Pesquisadora do GRUPESS. E-mail: anaruthmacedo@ yahoo.com.br

****** Enfermeira. Mestra e doutora em Enfermagem. Professora do Curso de graduação em enfermagem e do CMACCLIS da UECE. Fortaleza, Brasil. Pesquisadora do Grupo de Pesquisa Saúde da Mulher e Família. E-mail: anavirginiamf@aol. com
} 


\section{RESUMEN}

El presente artículo discute la posibilidad de cambios en las prácticas de enfermería por medio del cuidado crítico y creativo, y propone la educación en salud como instrumento para ello. Se presenta, de modo general, la propuesta educativa de Paulo Freire, destacando cómo sus principios pueden superar el modelo actual, que colabora escasamente en la emancipación de los sujetos participantes en el proceso del cuidado.

Palabras clave: Cuidado en enfermería; educación en salud; educación en enfermería.

Fecha recepción: 25/07/06 Fecha aceptación: 25/06/09

\section{UMA APROXIMAÇÃO AO TEMA}

A enfermagem tem importante papel na consolidação de uma sociedade mais justa e democrática, pois, mediante o cuidado, ela tem a oportunidade de educar o outro para a saúde, fazendo com que ele mobilize os próprios recursos para manter-se saudável, tornando-se mais autônomo. Além disso, as práticas educativas, quando desenvolvidas numa perspectiva conscientizadora, permitem que o indivíduo exerça mais plenamente a sua cidadania, diminuindo a exclusão social.

O trabalho de educação em saúde aparece então como instrumento capaz de transformar nossa prática profissional, conferindo ao cuidado características de uma atividade crítica e criativa.

Inicialmente, para uma melhor compreensão do assunto, tecemos algumas considerações acerca do cuidado crítico de enfermagem, entendido como um processo de reflexão, de introspecção pessoal sobre nossas ações e maneiras de cuidar. Este processo, embora realizado de maneira individual, desafia formas tradicionais de pensar e agir, centrando o cuidado na pessoa humana, ajudando o outro a crescer e a se realizar plenamente, facilitando o nosso reencontro com a verdadeira essência de nossa prática, e produzindo ações coletivas transformadoras, que valorizem a nossa profissão.

Somente a partir de uma reflexão crítica acerca da realidade em que nos encontramos e realizamos nossas ações, é que poderemos ousar nela intervir e modificar, nos emancipando e emancipando aquele de quem cuidamos. $\mathrm{O}$ cuidado deve favorecer o desenvolvimento humano, potencializando as habilidades do sujeito para cuidar de si, capacitando-o para trilhar o seu caminho, romper com relações de dominação excludentes presentes na sociedade, fazendo-o conquistar cenários próprios de cidadania, chagando a emancipá-lo do cuidado $(1,2)$.

Percebe-se, portanto, que o cuidado, assim embasado, adquire uma dimensão libertadora dos atores envolvidos no processo de cuidar, e que o pensamento crítico está relacionado intrinsecamente com o pensamento criativo, na medida em que este último nos permite buscar possibilidades de ir além, de transcender.

Neste sentido, dando continuidade à nossa reflexão, destacamos a importância da criatividade para o cuidado. Esta capacidade humana aparece como um instrumento básico para o cuidar, que estimula o crescimento individual e coletivo, impulsiona a humanidade rumo às descobertas, conferindo ao ser humano a capacidade de associar idéias que estimulem seu ajustamento ao ambiente que o cerca, aperfeiçoando-o e/ou modificando-o; propiciando o caminho para a resolução de situações não rotineiras (3).

$\mathrm{O}$ ato de cuidar é perceber o TODO, é enxergar de uma forma global, criativa e criadora, e a essência da pessoa criativa consiste na sua capacidade de estar apaixonada, enamorada por aquilo que está fazendo, nas coisas nas quais acredita e credita suas expectativas e esperanças (4). 
Para Baraúna (4), "A criatividade é perseverança e ousadia, um forte sentido de perceberse refletido na capacidade de realizar e criar o novo, transformar o velho".

\section{CUIDADO CRÍTICO E CRIATIVO EM ENFERMAGEM: CAMINHO POSSÍVEL}

Conceber um cuidado pautado na criticidade e na criatividade a partir do trabalho de educação em saúde, conforme a idéia que lançamos no início deste artigo, é aparentemente uma tarefa simples. Ocorre, entretanto, que há uma desvirtualização das práticas educativas em saúde quanto à sua execução, criando-se estratégias desinteressantes e ineficazes.

Entendendo educação em saúde como: "quaisquer combinações de experiências de aprendizagem delineadas com vistas a facilitar ações voluntárias conducentes à saúde" (5), daí se apreende que a chamada pedagogia tradicional (predominante na atualidade) não atende a esses princípios, uma vez que ela desconsidera o saber dos aprendizes, colocando o educador como detentor do único saber que é válido, não admitindo, portanto, que o próprio indivíduo busque ativamente melhores condições de vida e saúde, a partir de suas experiências.

A pedagogia tradicional confunde "ensinar" com "transmitir", tornando o indivíduo agente passivo da aprendizagem, e torna evidente a necessidade de o educador assumir um novo papel, o de facilitador do conhecimento, que deve ser buscado pelo aprendiz (6).

Assim, acreditamos que a proposta de Paulo Freire é mais adequada, pois sua educação problematizadora, democrática, visualiza o ser humano como um ser histórico, submerso em condições espaciotemporais, refletindo de maneira crítica sobre a sua existência, com capacidade para transformar-se e buscar ser mais livre (7).

A educação deve, então, ser vista como uma troca de experiências entre educador e educando, relação na qual um colabora para a aprendizagem do outro, sendo esta permuta inesgotável.

O saber não científico apresentado pela clientela, não reconhecido e não valorizado, parece descredenciá-la para compreender a saúde-doença e para exercer o poder de atuar sobre este processo. E valorizar e respeitar o saber do cliente sobre si, sobre o seu cotidiano vivido, estimula a que o seu eu e que vive no cotidiano se tornem objeto de seu pensamento, da sua reflexão, fortalecendo o cuidado do seu eu e ampliando o auto-conhecimento $(8,9)$.

É urgente a necessidade de reconhecer o cliente como sujeito de sua própria vontade, do seu próprio cuidado, com direitos e deveres, enfim, como cidadão, para construir uma relação simétrica, democrática, com o cliente, uma relação de mutualidade, com respeito e responsabilidades recíprocas, de aprendizado, de respeito à sua historicidade e unicidade (10).

Assim, com este entendimento da importância de um processo educativo compartilhado, participativo, é que fundamentamos nossa discussão na defesa de emprego da proposta de Paulo Freire nas ações de Educação em Saúde como instrumento para o alcance do cuidado crítico e criativo em enfermagem.

\section{CUIDADO E EDUCAÇÃO: INTEGRAÇÃO NECESSÁRIA}

A Educação em Saúde faz parte do cuidado de enfermagem, pois na essência somos educadores, embora Educação em Saúde por muito tempo tenha sido associada somente a procedimentos didáticos de transmissão de conhecimento em saúde, visando principalmente a medidas preventivas. Ainda hoje, muitos profissionais de saúde se mantêm orientados por essa visão reducionista e positivista da 
Educação em Saúde, entretanto a mudança de paradigma possibilita a compreensão da ciência em um nível bem mais crítico e criativo, no qual Educação e Saúde passam a ser entendidas como áreas de conhecimento humano que, integradas, revigoram o exercício da cidadania.

O cuidado é o instrumento de trabalho do enfermeiro e não pode ser visto apenas pelo lado técnico e biomédico, pois o foco do cuidado está centrado no Homem e este é um ser complexo que pensa, age e interage, que tem aspectos biológicos, psicológicos, sociais, culturais e está inserido em um contexto histórico, político e econômico que norteia suas ações, requerendo, portanto, de cuidados (11).

Soares, Lunardi (10) destacam que cada vez mais os enfermeiros estão preocupados e inconformados com o processo de "coisificação" das pessoas, tanto dos clientes como, possivelmente, de si próprios, por se sentirem impotentes para alcançar maiores rupturas neste vivido, e têm optado por direcionar seu olhar crítico, investigador e de estudo para o cotidiano de sua prática, numa tentativa de apontar possibilidades de uma mudança como estratégias de fortalecimento de uma categoria profissional comprometida consigo e com os direitos daqueles que buscam os seus cuidados.

Portanto, a educação precisa ser valorizada no processo de cuidar, pois não podemos exercer uma prática que atua no cliente, mas com o cliente, fazendo com que o outro participe do cuidado e também se responsabilize por ele. Dessa forma a Educação em Saúde tem o papel de reaver a cidadania, pois o cliente se sentirá valorizado e o cuidado ultrapassará as barreiras institucionais e alcançará as comunidades.

A reflexão crítica sobre a prática se torna uma exigência da relação teoria/prática sem a qual a teoria pode virar idéias que não saem do papel e a prática se transformar em ativismo (12).

A educação e o cuidado são interde- pendentes. A partir do momento em que o enfermeiro está cuidando, ele está educando e aprendendo. Além disso, são medidas que rompem as barreiras institucionais e individuais, adentram a comunidade e visam ao coletivo, não podendo apenas estar voltada para o atendimento dos interesses políticos e econômicos hegemônicos. O profissional de saúde deve ser um educador, transformador, emancipador e libertador, que almeja a mudança de comportamento da clientela, a fim de que atinja a qualidade de vida, provocando a transformação e a recriação da realidade instituída $(13,14)$.

Ao lado da conscientização, a mudança é um "tema gerador" da prática teórica de Paulo Freire, pois o papel da educação é o de conscientizar, com o objetivo de mudar uma realidade não desejada, contudo, utilizando a liberdade, o diálogo, com o compromisso de passar de uma consciência ingênua para uma consciência crítica.

Isto significa que o papel fundamental do homem é o de ser sujeito e não objeto de transformação, tarefa que dele exige, durante sua ação sobre a realidade, um aprofundamento da sua tomada de consciência da realidade, objeto de atos contraditórios daqueles que pretendem mantê-la como está e dos que pretendem transformá-la. Portanto, se a vocação ontológica do homem é a de ser sujeito e não objeto, só poderá desenvolvêla na medida em que, refletindo sobre suas condições, introduz-se nelas, de modo crítico e criativo, não agindo como mero espectador, mas intervindo nela (15).

E, neste contexto, entra a importância de o cuidado estar em constante inter-relação com a educação, pois cuidar envolve comunicação e interação e, a partir do momento em que o enfermeiro está cuidando, ele está interagindo, trocando experiências, rompendo assim a visão de cuidado estritamente técnico e passando a praticar um cuidado crítico, de preocupação com o outro e embasado cientificamente. Não é simplesmente remediar, é descobrir os porquês e agir. 
Ao prestar o cuidado, o enfermeiro não pode perder de vista o indivíduo como cidadão, e compreendê-lo de forma holística e não simplesmente focalizar sua atenção para os aspectos biológicos, sendo a escuta fundamental e imprescindível nesse processo cuidar/educar, pois constitui etapa inicial para haver o diálogo e conseqüentemente a interação, possibilitando ao enfermeiro entrar em contato com o conhecimento do indivíduo/ coletividade, a fim de direcionar as práticas educativas.

Para Correa, Souza e Saeki (16) entrar em contato com o outro e consigo, gera uma inquietação que leva ao questionamento das "conservas culturais" do mundo do trabalho da saúde e da enfermagem, bem como, da própria formação do profissional, podendo desenvolver a sensibilidade e a capacidade crítica para compreender e transformar a realidade de cuidado.

Educar significa colocar o indivíduo em contato com os sentidos que circulam em sua cultura, para que, os assimilando, possa nela viver (17). Essa assimilação, no entanto, não deve subentender uma atitude passiva do sujeito, pois não se trata de impor sentidos ao educando, de adaptá-lo a conceitos preexistentes.

Portanto, a atuação do profissional de saúde junto à comunidade é a de mobilizá-la na busca das melhores condições de saúde, mediante interação dialógica, e admitindo os saberes preexistentes para integrá-los na formulação do conhecimento, pois, para Paulo Freire, o conhecimento é feito de forma integradora e interativa (18).

A Educação em Saúde é a ferramenta que visa à mudança de comportamento para o exercício da cidadania (15). Esta mudança é viabilizada quando o profissional de saúde reconhece e valoriza o saber socialmente elaborado pela clientela em seu ambiente. Por meio deste reconhecimento, ocorrerá a produção efetiva de novos conhecimentos, modificando o comportamento de saúde da clientela, objetivando atingir a qualidade de vida.
Para que possamos exercer um cuidado crítico e criativo, precisamos compreender a educação como um instrumento que auxilia no cuidado. Não deve ser, contudo, uma educação de transmissão, na qual o enfermeiro se vê como o detentor do saber, o que lhe dá poder para interferir e decidir pelas pessoas de quem está cuidando, mas sim educar na proposta de Paulo Freire, em que educação é uma ferramenta de conscientização e transformação cujo eixo norteador é a participação do indivíduo nas decisões.

\section{CONSIDERAÇÕES FINAIS}

A Educação em Saúde fundamentada nas concepções de Paulo Freire representa/significa um caminho para promover o cuidado crítico e criativo que permite transformar a atual prática de enfermagem, já avaliada como tecnicista por muitos pesquisadores. Os preceitos básicos desse teórico favorecem a compreensão da importância de estabelecer um relacionamento pautado em canais abertos de comunicação que permitam a elaboração conjunta da assistência.

Assim, a convergência entre as práticas educativas emancipatórias, aqui representada por Paulo Freire, e o cuidado de enfermagem, é um desafio cuja superação favorecerá o desenvolvimento de uma nova visão do indivíduo e, conseqüentemente, uma prática realmente mais humana, afetiva e efetiva.

Entende-se, todavia, que uma mudança como essa, a qual envolve mesmo a superação de um paradigma - positivista - já contestado teoricamente (mas que resiste na prática), consiste num complicado processo que envolve um esforço coletivo.

Assim, espera-se que a discussão apresentada sobre o tema possa favorecer a descoberta de estratégias facilitadoras dessa mudança, possibilitando o aprimoramento do cuidado de enfermagem. 


\section{REFERÊNCIAS}

1. Pires M.R.G.M. Enfermeiro com qualidade formal e política: em busca de um novo perfil [dissertação]. 2001. Brasília (DF). Universidade de Brasília/UNB.

2. Pires M.R.G.M. Politicidade do cuidado como referência emancipatória para a enfermagem: conhecer para cuidar melhor, cuidar para confrontar, cuidar para emancipar. Revista Latino-americana de Enfermagem. 2005; 13(5): 729-736.

3. Sá A.C. de, Fugita R.M.I. A criatividade como instrumento básico em enfermagem. In: Cianciarullo T.I. Instrumentos básicos para o cuidar: um desafio para a qualidade da assistência. São Paulo. 1996. Ed. Atheneu, 47-60.

4. Baraúna T. Criatividade: uma necessidade para a enfermagem. Revista Nursing. 2001; 33(4): 8-9.

5. Candeias N.M.F. Conceitos de educação e de promoção em saúde: mudanças individuais e mudanças organizacionais. Revista Saúde Pública. 1998; 31(2): 209-213.

6. Fonseca L.M., Scochi C.G.S., Mello D.F. Educação em saúde de puérperas em alojamento conjunto neonatal: aquisição de conhecimento mediado pelo uso de um jogo educativo. Revista Latino-americana de Enfermagem. 2002; 10(2): 166-171.

7. Barroso G.T., Vieira N.F., Varella Z.M. Educação em saúde no contexto da promoção humana. Fortaleza. Edições Demócrito Rocha. 2003.

8. Lunardi V.L. A ética como o cuidado de si e o poder pastoral na enfermagem. Florianópolis. Universidade Federal de Santa Catarina/UFSC. 1999.

9. Bellato R., Pereira W.R., Maruyama S. A.T.,
Oliveira P.C. A convergência cuidadoeducação-politicidade: Um desafio a ser enfrentado pelos profissionais na garantia aos direitos à saúde das pessoas portadoras de estomias. Texto contexto-enfermagem. 2006; 15 (2): 334-342.

10. Soares N.V., Lunardi V.L. A problematização dos direitos do cliente implicando na problematização dos direitos dos profissionais de enfermagem. Revista Ciencia y Enfermería. 2003; IX(1): 65-76.

11. Silva L.F. Cuidado de enfermagem em terapia intensiva cardiológica: hermenêutica do conceito fundamentada na fenomenologia heideggeriana [tese]. Fortaleza (CE). Universidade Federal do Ceará/UFC. 2002.

12. _. Pedagogia da autonomia: saberes necessários à prática educativa. São Paulo. Ed. Paz e Terra. 2004.

13. Silva S.H.S. Professor de medicina: diálogos sobre sua formação docente [tese]. São Paulo. Pontifícia Universidade Católica/ PUC. 1997.

14. Alvim N. A. T., Ferreira M.A. Perspectiva problematizadora da educação popular em saúde e a enfermagem. Texto contextoenfermagem. 2007; 16(2): 315-319.

15. Freire P. Educação e mudança. (27 ed.) São Paulo. Ed. Paz e Terra. 2003.

16. Correa A.K., Souza M.C.B.M; Saeki T. Psicodrama pedagógico: estratégia para o ensino em enfermagem. Ciencia y Enfermería. 2004; X(2):15-19.

17. Duarte Júnior J.F. Fundamentos estéticos da educação (5 ed.). Campinas. Ed. Papirus. 1998.

18. McHarem P., Leonard P., Gadotti M. Paulo Freire, poder, desejo, e memórias da libertação. Porto Alegre. Ed. Artes Médicas. 1999. 